\title{
The 'dirty lip' trick
}

Nicholas Wilson Jones MB BCh MSc MRCS(Ed) FRCS(Plast), Cynthia Verchere MD FRCSC

$\mathrm{T}$ he lips are complex anatomical structures with significant psychosocial and functional importance. The wet-dry line or 'red line' on the lip represents the transition from oral mucosa to lip vermilion, and is one of the essential anatomical landmarks required for accurate reconstruction of the lip.

Identification of the wet-dry line is important in cleft lip surgery, particularly if a triangular vermilion flap from the lateral element is used to augment the deficient vermilion on the medial side, as described by Noordhoff (1).

During lip surgery, landmarks and presurgical marking are often distorted by intraoperative edema and local anesthetic infiltration; standard methods for maintaining these landmarks in the cutaneous lip, such as tattooing, are not as effective in the vermilion. The authors present a simple yet effective way of identifying the red line during surgery.
The immediate response when attempting to identify the wet-dry junction is to clean the lip of any dried blood for better visualization. The authors simply suggest leaving the lip 'dirty'; the blood adheres to the wet mucosa and not to the dry, thus clearly and consistently identifying the junction between wet and dry mucosa (Figures $1 \mathrm{~A}$ and 1B).

The authors have been surprised at how often such a simple technique has been useful in cleft and other forms of reconstructive lip surgery.

\section{REFERENCE}

1. Noordhoff MS. Reconstruction of vermilion in unilateral and bilateral cleft lips. Plast Reconstr Surg 1984;73:52-61.

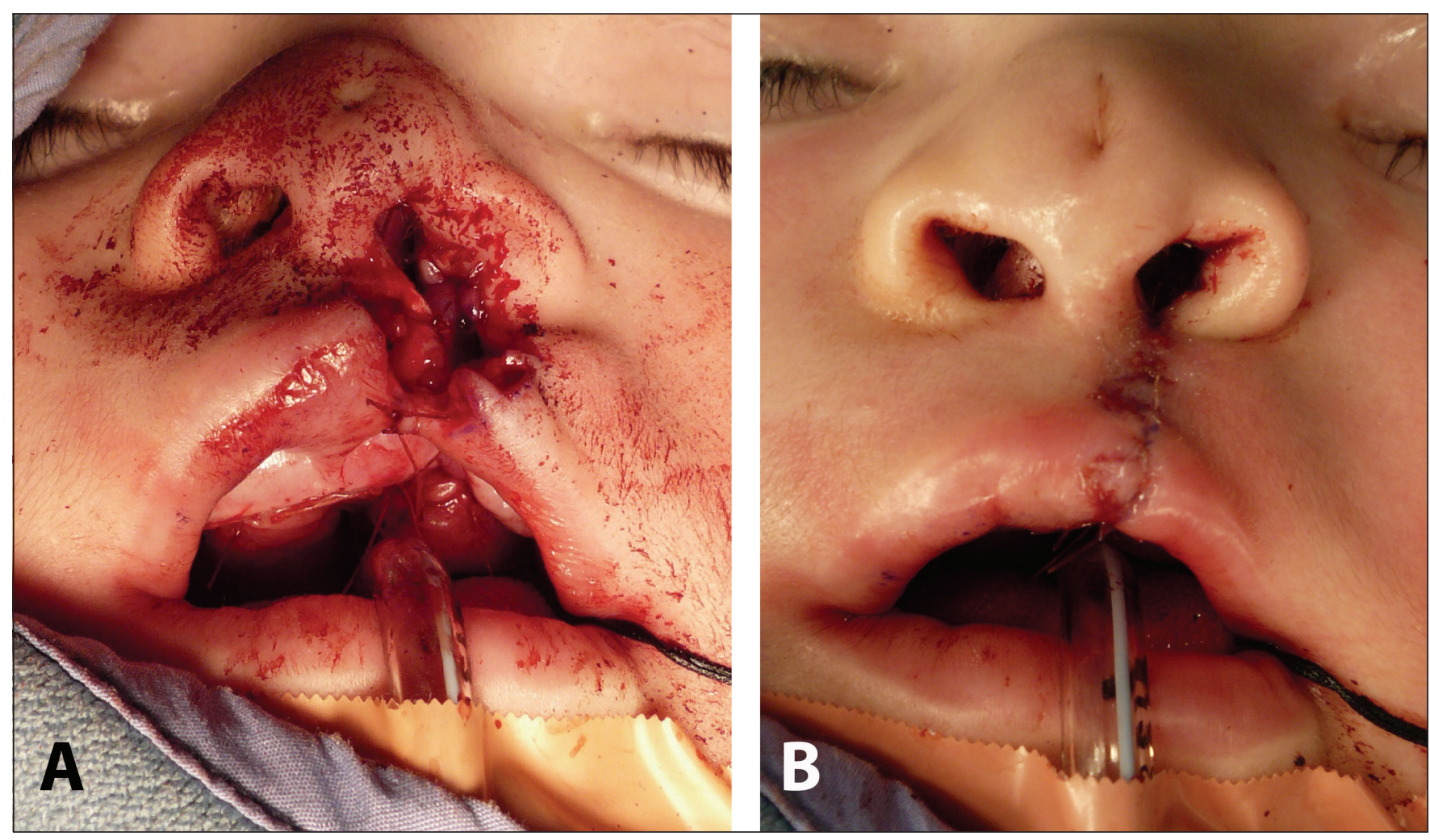

Figure 1) A and B Leaving the lip 'dirty' during cleft lip surgery clearly identifies the division between wet and dry vermilion 